\title{
Chronic thrombocytopenia and skeletal dysplasia in a 14-year-old girl with cystic fibrosis
}

\author{
Jan C. Thomassen ${ }^{1}$, Ilse J. Broekaert ${ }^{1}$, Friederike Körber ${ }^{3}$, Thorsten Simon ${ }^{2}$, Ernst Rietschel ${ }^{1}$ and Silke van Koningsbruggen-Rietschel ${ }^{1}$ \\ ${ }^{1}$ Cystic Fibrosis Center Cologne, University Children's Hospital Cologne, Faculty of Medicine, University of Cologne, Germany \\ ${ }^{2}$ Pediatric Hematology and Oncology, University Children's Hospital Cologne, Germany \\ ${ }^{3}$ Department of Pediatric Radiology, University Children's Hospital Cologne, Germany
}

Abbreviations: CF: Cystic Fibrosis; SBDS: Shwachman-BodianDiamond Syndrome; PI: Pancreas Insufficiency; NOF: Non-Ossifying Fibroma

A 14-year-old Caucasian female with genetically confirmed diagnosis of cystic fibrosis (CF) ( $\triangle$ F508/N1303K) and chronic exocrine pancreatic insufficiency (PI) presented with increasing pain of both knees. She developed a progressive chronic thrombocytopenia without any clinical symptoms (Table 1). Autoimmunological, rheumatological and infectiological causes were ruled out and the diagnosis of Shwachman-Bodian-Diamond Syndrome (SBDS) was established in 2009. Molecular genetic analysis detected a heterozygous missensemutation in the SBDS-gene (c.127G $>$ T for p.Val43Leu) of unknown clinical significance.

X-rays of both knees showed bilateral cystic structures of the distal femoral diametaphysis (Figure 1). Magnetic resonance imaging (Figure 2) supported the diagnosis of non-ossifying fibroma (NOF) without evidence of malignancy confirmed by histopathological results. A bone marrow biopsy was performed which excluded major complications of SBDS (myelodysplastic syndrome and acute myeloid leukemia). In consequence of the persisting pain despite analgesic treatment, curettage and spongioplasty of the bone lesions were performed. The pain resolved four weeks after surgical intervention while the asymptomatic thrombocytopenia further persisted.

The combination of exocrine PI, chronic thrombocytopenia and skeletal dysplasia represents the characteristic phenotype of SBDS and allows the clinical diagnosis without genetic confirmation [1,2]. The detection of mutations in the SBDS-gene may lead to an early diagnosis of SBDS before the full clinical spectrum is present. However, mutations

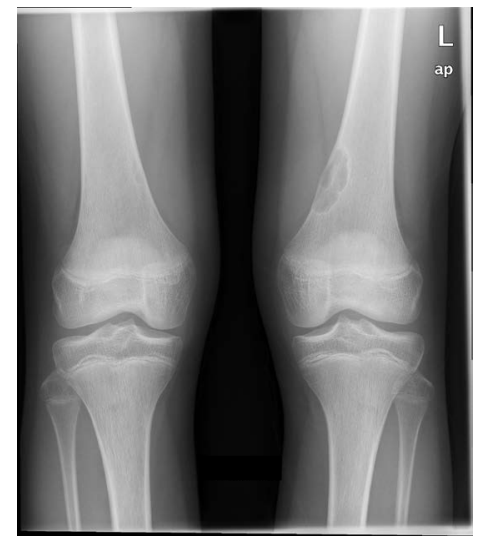

Figure 1. Hyperlucent lesions of the right and left femoral diametaphysis (X-ray a.p.) with thin sclerotic rims. in an homozygous status can only be found in approximately $90 \%$ of SBDS-patients $[1,3]$.

This case demonstrates the difficulties in establishing the diagnosis of SBDS especially in patients with other chronic diseases sharing similar symptoms (e.g. PI which was contributed solely to CF after birth). PI in SBDS can improve within the first years of life whereas in $\mathrm{CF}$ the PI is irreversible due to fibrotic changes in the organ.

Quarterly blood counts during the routine CF-visits were scheduled and with regard to haematological complications, annual bone marrow biopsies were recommended [1].

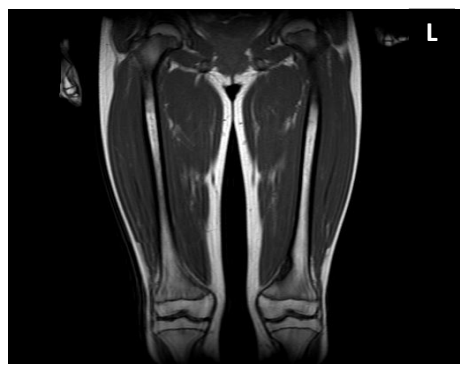

Figure 2. $3.8 \mathrm{~cm} \times 1.2 \mathrm{~cm}$ measured, exentric lesion of the right and left femoral diametaphysis appearing hypointense in T1WI with peripheral low signal rims, which correspond to the sclerotic border (Coronal T1-weighted MRI-sequence).

Table 1. Blood count over the past years (2009 diagnosis of SBDS; 2014 non-ossifying fibromas) -annual lowest values are shown.

\begin{tabular}{|c|c|c|c|c|}
\hline Year & $\begin{array}{c}\text { Thrombocytes } \\
\text { (/nl) } \\
\text { range: } 150-400)\end{array}$ & $\begin{array}{c}\text { Leucocytes } \\
\text { (x1E'/) (normal } \\
\text { range:4.5-17.5) }\end{array}$ & $\begin{array}{c}\text { abs. Neutrophils } \\
\text { (x1E'/l) }(\text { normal } \\
\text { range: } 1.5-9.9)\end{array}$ & $\begin{array}{c}\text { Hemoglobin } \\
\text { (g/dl) } \text { (normal } \\
\text { range: } 11.5-15.0)\end{array}$ \\
\hline 2009 & 88 & 4.05 & 2.44 & 11.4 \\
\hline 2010 & 110 & 4.75 & 2.67 & 11.6 \\
\hline 2011 & 80 & 3.92 & 1.97 & 12.5 \\
\hline 2012 & 81 & 3.86 & 1.64 & 12.2 \\
\hline 2013 & 79 & 3.79 & 0.48 & 12.7 \\
\hline 2014 & 30 & 4.12 & 1.95 & 11.2 \\
\hline 2015 & 71 & 3.40 & 1.67 & 12.2 \\
\hline
\end{tabular}

Correspondence to: Jan Christoph Thomassen, CF Study Center Cologne, University Hospital Cologne Kerpenerstr. 62, 50924 Cologne, Germany, Tel: +49-221-478-4492; Fax: +49-221-478-3330; E-mail: Jan.thomassen@uk-koeln.de

Key words: ystic fibrosis, chronic thrombocytopenia, skeletal dysplasia, Shwachman-Bodian-Diamond syndrome

Received: October 20, 2016; Accepted: November 11, 2016; Published: November 15, 2016 


\section{References}

1. Dror Y, Donadieu J, Koglmeier J, Dodge J, Toiviainen-Salo S, et al. (2011) Draft Consensus guidelines for diagnosis and treatment of Shwachman-Diamond Syndrome. Ann N Y Acad Sci 1242: 40-55. [Crossref]

2. Myers KC, Bolyard AA, Otto B, Wong TE, Jones AT, et al. (2014) Variable clinical presentation of SDS: update from the North American SDS Registry. J Pediatr 164: 866-70. [Crossref]

3. Boocock GR, Morrison JA, Popovic M, Richards N, Ellis L, et al. (2003) Mutations in SBDS are associated with Shwachman-Diamond syndrome. Nat Genet 33: 97-101. [Crossref]

Copyright: (C2016 Thomassen JC. This is an open-access article distributed under the terms of the Creative Commons Attribution License, which permits unrestricted use, distribution, and reproduction in any medium, provided the original author and source are credited. 